\title{
PREVALENCE AND FACTORS ASSOCIATED WITH SYMPTOMS OF ANXIETY, STRESS AND DEPRESSION IN MEDICAL STUDENTS
}

Marília Sonda1, Gustavo Olszanski Acrani², Rogério Tomasi Riffel${ }^{2}$

1 Student, Universidade Federal da Fronteira Sul (UFFS), Passo Fundo, RS, Brasil.

2 Master, Universidade Federal da Fronteira Sul (UFFS), Passo Fundo, RS, Brazil.

GOAL: Evaluate the prevalence and factors associated with anxiety, stress and depression symptoms in students from two medical schools in Passo Fundo (RS), a public one and a private.

BACKGROUND: It is estimated that $15 \%$ to $25 \%$ of college students present some type of psychiatric disorder during their academic training. In this context, the prevalence of anxiety and depression among medical students is higher than in the general population. Psychological sufferings during medical training are associated with poor academic performance, unwillingness to care for the chronically ill, and decreased empathy, factors that affect the quality of care provided by the future physicians.

MATERIALS AND METHODS: Cross-sectional study with 377 students. The Beck Inventory of Anxiety, Stress Symptoms for Adults from Lipp and Beck Depression were used. Sociodemographic and behavioral variables collected by structured questionnaire.

\section{PREVALENCE OF OUTCOMES}

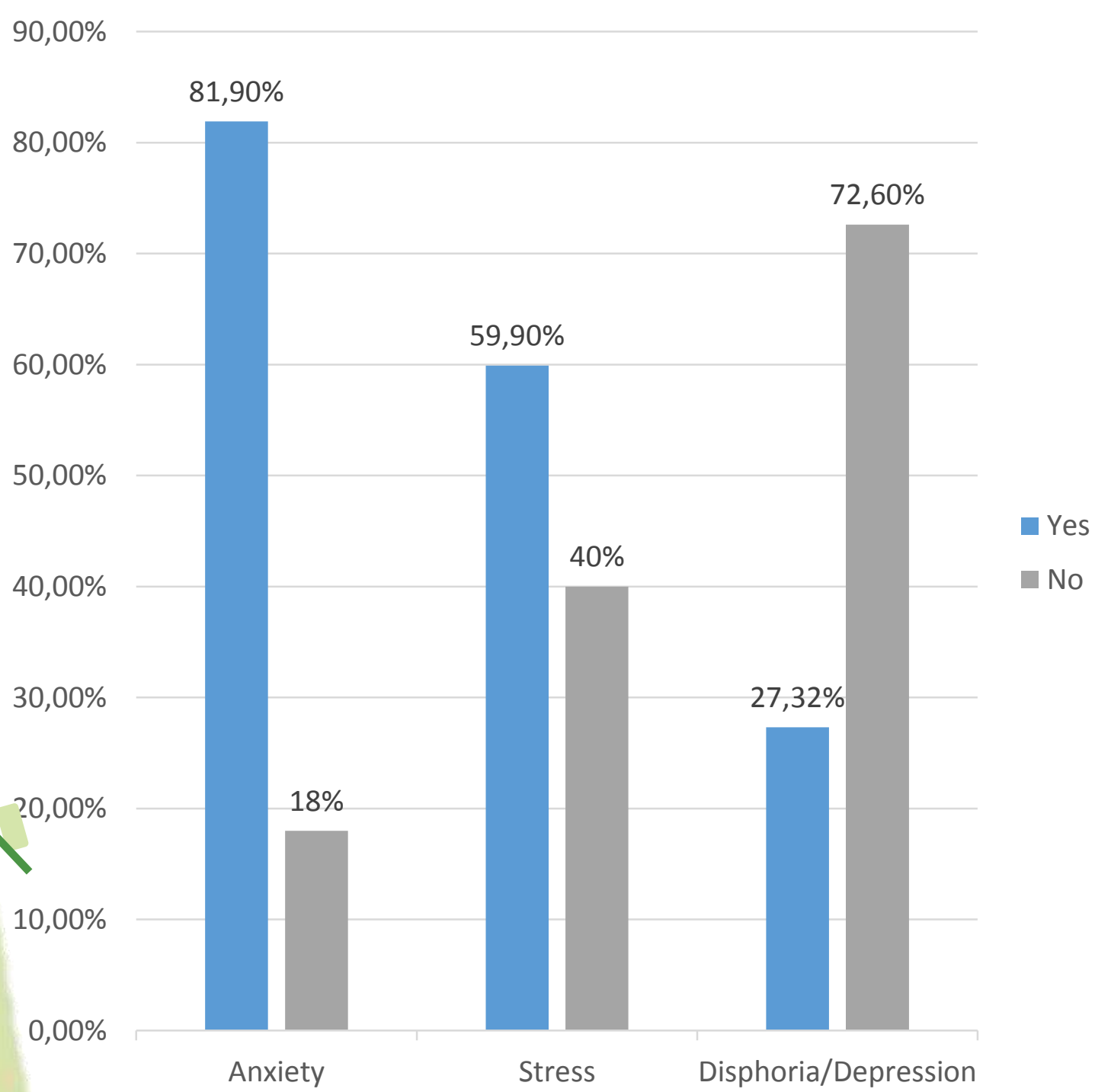

\section{SOURCES}

Giglio JS. Bem-estar emocional em estudantes universitários [tese]. Campinas (SP): Unicamp; 1975

Vasconcelos TC, Dias BRT, Andrade LR, Melo GF, Barbosa L, Souza E. Prevalência de Sintomas de Ansiedade e Depressão em Estudantes de Medicina. Rev. bras. educ. med., Rio de Janeiro, v. 39, n. 1, p. 135-142, Mar. 2015.

Rotenstein LS, Ramos MA, Torre M, Segal JB, Peluso MJ, Guille C, et al. Prevalência de Depressão, Sintomas Depressivos e Ideação Suicida entre Estudantes de Medicina: Uma Revisão Sistemática e Meta-Análise . JAMA. 2016; 316 (21): 2214-2236
RESULTS: Females were positively associated with anxiety. Females, stage of the course and satisfaction with the course were positively associated with stress. Satisfaction with the course has a positive association with dysphoria or depression., while the practice of physical exercises, negative association. The prevalence of outcomes is illustrated in Fig. 1. Figure 2 shows the distribution of positive outcomes for the anxiety, stress, and depression scales per semester studied in percentage.

CONCLUSION: High levels of depression and anxiety were observed in medical students, compared to the general population. There are marked differences between the course semesters in the stress variable. There is no significant difference between public and private universities. The gender variable influences anxiety and stress levels, but not depression. Satisfaction with the course is associated with levels of stress and depression. Practicing physical exercise regularly is a protective factor against the outcome of depression.

\section{DISTRIBUTION OF OUTCOMES PER SEMESTER}

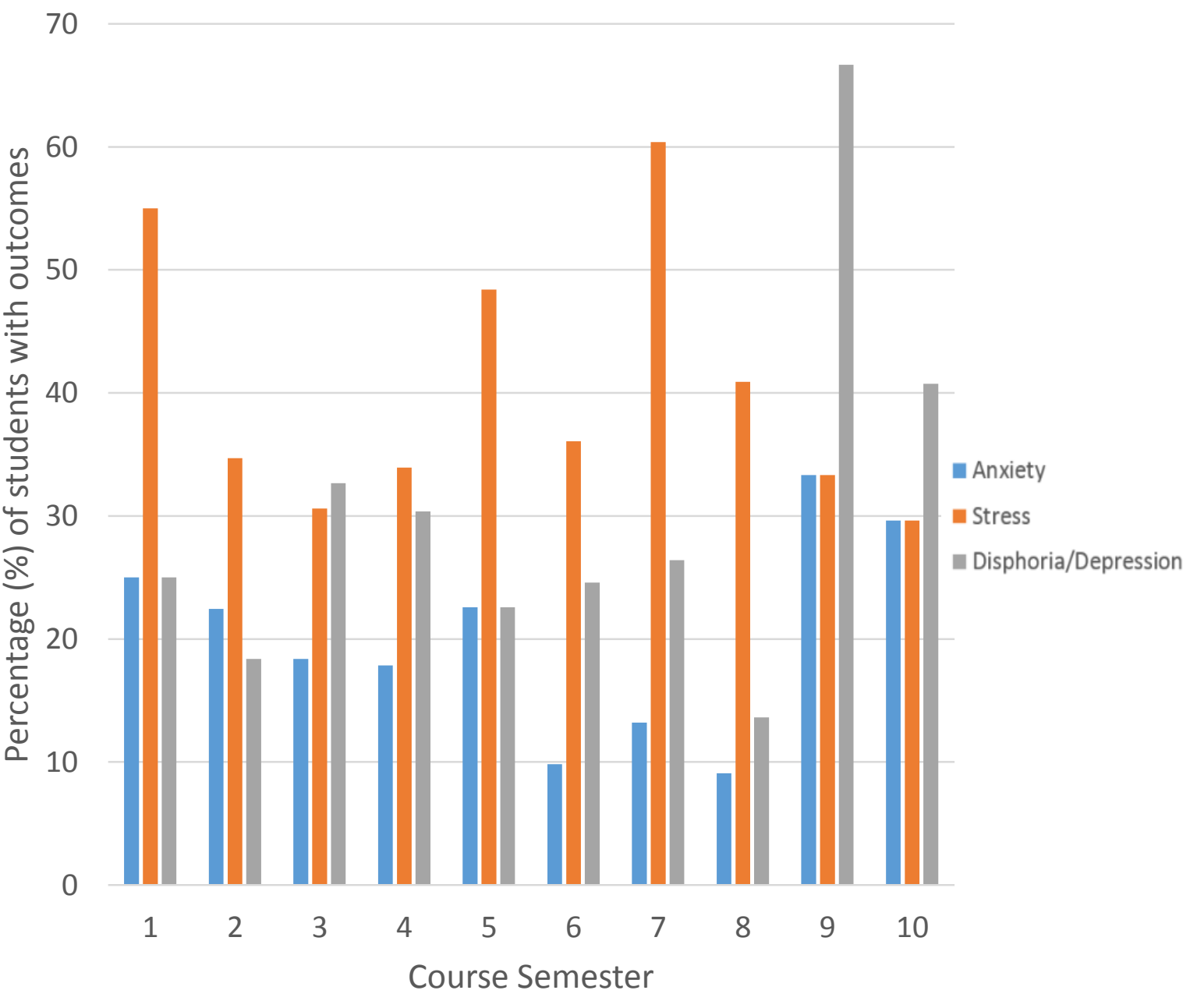

Figure 1: The statistical frequencies of each were calculated in relation to the total number of students in each phase of the course. 